\title{
МЕТОДЫ ПОВЫШЕНИЯ КОНТРОЛЯ КАЧЕСТВА ГОСТИНИЧНЫХ УСЛУГ
}

Гречухина О.A. Никольская Е.Ю. кандидат экономических наук, доцент Российский Экономический Университет им. Г.В. Плеханова, г. Москва

Аннотация: В данной статье рассматривается система управления качеством гостиничных услуг и методы их повышения.

Ключевые слова: гостиница, система управления качеством, классификация факторов, методы повышения качества гостиничных услуг.

\section{METHODS FOR IMPROVING THE QUALITY CONTROL OF HOTEL SERVICES}

\section{Grechukhina O.A. Nikolskaya E.Yu.}

\begin{abstract}
This article discusses the quality management system of hotel services and methods to improve them.

Key words: hotel, quality management system, classification of factors, methods of improving the quality of hotel services.

\section{Актуальность.}

Качество гостиничных услуг является мотивацией при выборе отеля потребителем, а также обеспечивает конкурентное преимущество. Качество оказываемых гостиничных услуг является таким фактором, к которому, сейчас, проявляется большой интерес. В условиях современного рынка важной частью гостиничного предприятия является изучение и повышение качества гостиничных услуг. Главная задача гостиничного предприятия - это повышения качества гостиничных услуг и их контроль.
\end{abstract}

\section{Введение.}

Индустрия гостеприимства в большей части нацелена на своих постоянных и потенциальных гостей. Для любой гостиницы важно следить не 
только за уровнем своих услуг, но и за качеством их предоставления, и постоянно его повышать.

Для повышения качества гостиничных услуг рекомендуется: постоянно отслеживать отзывы гостей о качестве услуг на сайтах tripadvistor.ru, marriott.com.ru, booking.com, также определять конкурентное преимущество отеля на основе анализа конкурентов, SWOT-анализа собственного отеля; методом Тайный гость, контроль соблюдения Стандартов обслуживания; оценка удовлетворённости персонала и др. Данные рекомендации позволят своевременно реагировать на отзывы и жалобы гостей, значительно позволят повысить рейтинг отеля, увеличит лояльность гостей и снизит текучесть кадров.

Виды качества гостиничных услуг бывают материальные и нематериальные.

В материальные услуги гостиничного предприятия входит номерной фонд, оборудование, фитнес-центр и т.п. В нематериальные услуги гостиничного предприятия входят: сервис, атмосфера дружелюбие и т.п.

Все показатели качества услуг можно классифицировать на:

1. количественные (время ожидания и предоставления услуги; характеристики оборудования, инструмента, материалов и т.п.; надежность оказания услуги; точность исполнения; полнота; уровень автоматизации и механизации; безопасность; полнота оказания услуги и т.п.);

2. качественные (вежливость, доступность персонала, чуткость, компетентность, доверие персоналу, уровень профессионального мастерства, эффективность контактов исполнителей и клиентов, искренность и т.п.).

При этом показатели качества услуг следует подразделить на ряд групп, например:

1. функционального назначения;

2. надежности;

3. безопасности;

4. экологичности;

5. эстетичности;

6. социальной значимости (оригинальности, престижности, соответствия моде)

Целью проведенного исследования является разработка рекомендаций по повышению и контролю качества гостиничных услуг. Для достижения поставленной цели были решены следующие задачи: определена система 
управления качеством услуг в гостиничном предприятии; выявлены факторы, влияющие на качество гостиничных услуг; разработаны методы повышения качества гостиничных услуг.

\section{Результаты исследования.}

Понятие «качество услуги» можно рассматривать как комплекс, состоящий из трех элементов:

1. качество потенциала предприятия (технический элемент);

2. качество процесса (функциональный элемент);

3. социальное качество (социальный элемент).

Управление качеством услуг в гостинице - один из важнейших способов управления и организации деятельности гостиничного предприятия. Управление качеством в гостинице осуществляется путем реализации управленческих функций:

1. Принятие решений руководством предприятия в области политики качества

2. Исследования в области качества услуг, потребностей туристского рынка

3. Планирование качества и разработка необходимых мероприятий

4. Внедрение отраслевого стандарта качества

5. Обучение персонала в соответствии с квалификационными требованиями

6. Мотивация персонала и нормирование труда

7. Контроль качества

8. Реализация мероприятий

9. Взаимодействие с внешней средой

Для управления качеством в гостинице должны присутствовать следующие системы:

1. система, отвечающая за подбор персонала и его обучение;

2. система, осуществляющая контроль качества оказываемых услуг в гостинице.

3. система мониторинга удовлетворенности клиентов.

Эффективность управления качеством в гостинице оцениваются по следующим факторам:

1. эффективное маркетинговое управление;

2. отраслевой стандарт качества;

3. работа над совершенствованием производственных процессов; 
4. подбор служащих в соответствии $\quad$ с $\quad$ видом $\quad$ и профессиональных качеств;

5. наличие нормативов выработки;

6. развитая корпоративная культура.

Критерий оценки качества полученной услуги для потребителя — это степень его удовлетворенности. Критерий степени удовлетворенности клиента - желание вернуться еще раз и посоветовать это сделать своим друзьям и знакомым.

Основным документом, которые определяют качественное взаимоотношения между сотрудниками гостиницы и гостями являются "Правила предоставления гостиничных услуг №1085 в РФ".

На качественное обслуживание в гостиничном предприятии воздействуют следующие факторы:

1. Состояние материально - технической базы - это удобная планировка и качественная отделка помещений гостиницы, оснащение общественных помещений и жилых номеров комфортабельной мебелью и оборудованием, полные комплекты высококачественного белья и др.

2. Прогрессивная технология обслуживания - и способы уборки общественных помещений и жилых номеров; регистрацию и расчет с клиентами; рецептуру приготовления блюд и напитков в ресторанах и барах; формы обслуживания в торговых залах и др.

3. Высокий профессионализм и компетентность обслуживающего персонала, его умение и готовность четко, быстро и культурно обслуживать гостя.

4. Управление качеством обслуживания, что предусматривает разработку и внедрение стандартов качества, обучение персонала, контроль, корректировку, совершенствование обслуживания на всех участках деятельности гостиницы.

\section{Факторы гостиничных услуг.}

Качество гостиничных услуг формируется под воздействиями факторов, которые на них влияют. Факторы, которые положительно влияют на качество обслуживания во многом превосходит отрицательно влияющих. Рассмотрим немного подробнее их.

Факторы, положительно влияющие на качество обслуживания:

1. Гостеприимность персонала - это добродушные, улыбчивый персонал; 
2. Профессионализм работников - квалифицированный персонал;

3. Хорошо организованный процесс предоставления услуг - зависит от персонала, как он осведомлен об услугах гостиничного предприятия и умения его продавать;

4. Атмосфера доброжелательности и взаимопомощи в коллективе;

5. Постоянство качества обслуживания - это поддержание высокого уровня обслуживания гостей;

6. Оперативность работы - быстрота, организованность и качество работы.

Факторы, отрицательно влияющие на качество обслуживания:

1. Нехватка персонала - мало квалифицированных сотрудников;

2. Недостатки материально-технической базы;

3. Невысокий уровень заработной платы.

\section{Методы повышения качества гостиничных услуг}

На основе проведенного исследования были представлены следующие методы:

Первый метод - это стандартизация.

Стандартизация - это деятельность по установлению норм, правил и требований в целях обеспечения безопасности продукции, работ и услуг для окружающей среды, жизни, здоровья и имущества потребителя.

Второй метод - SWOT-анализ

SWOT-анализ - метод стратегического планирования, заключающийся в выявлении факторов внутренней и внешней среды организации и разделении их на четыре категории:

Strengths (сильные стороны),

Weaknesses (слабые стороны),

Opportunities (возможности),

Threats (угрозы).

Сильные (S) и слабые (W) стороны являются факторами внутренней среды объекта анализа, (то есть тем, на что сам объект способен повлиять); возможности $(\mathrm{O})$ и угрозы $(\mathrm{T})$ являются факторами внешней среды (то есть тем, что может повлиять на объект извне и при этом не контролируется объектом).

Третий метод - Внедрение Инновационных технологии

Инновационные технологии - это наборы методов и средств, поддерживающих этапы реализации нововведения. Различают различные 
виды инновационных технологий, такие как внедрение, тренинг (подготовка кадров и инкубация малых предприятий), консалтинг, трансферт, инжиниринг и другие.

Инновационные технологии можно условно поделить на два направления:

1. революционные (как изобретение реактивного двигателя),

2. эволюционные (которые просто усовершенствуют процесс или продукт).

Четвертый метод - Повышение квалификации персонала

Повышение квалификации - это один из видов профессионального обучения работников предприятия, которое проводится с целью повышения уровня теоретических знаний, совершенствования практических навыков и умений сотрудников организации в связи с постоянно повышающимися требованиями к их квалификации.

Пятый метод - Стандарты обслуживания

Стандарты обслуживания - это методические и организационноинструктивные документы, которые разрабатываются вместе с экономистами и специалистами компании.

Шестой метод - Ресурсосберегающие технологии

Ресурсосберегающая технология - это технология, при которой потребление всех типов ресурсов сведено к рациональному (минимальному) уровню.

Седьмой метод - анализ конкурентов и разработка программы конкурентного преимущества

Восьмой метод - Система управления качеством

Система управления качеством (система качества) - это организационная структура, включающая взаимодействующий управленческий персонал, реализующий функции управления качеством установленными методами.

Применение данных методов ведет к повышению качества услуг, обеспечивающих:

1. Конкурентное преимущество

2. Стабильные доходы

3. Лояльность гостей 
Анализ качества на примере гостиницы «Courtyard by Marriott Paveletskaya»

Для того, чтобы улучшить качество обслуживания в гостинице «Courtyard by Marriott Paveletskaya» и установить контроль качества, нужно проанализировать посещаемость разных социальных групп.

Для того, чтобы узнать посещаемость разных социальных групп, мы составим и проанализируем карту гостя по данным с разных сайтов: Booking.com, Tripadvistor.ru и marriott.com.ru.

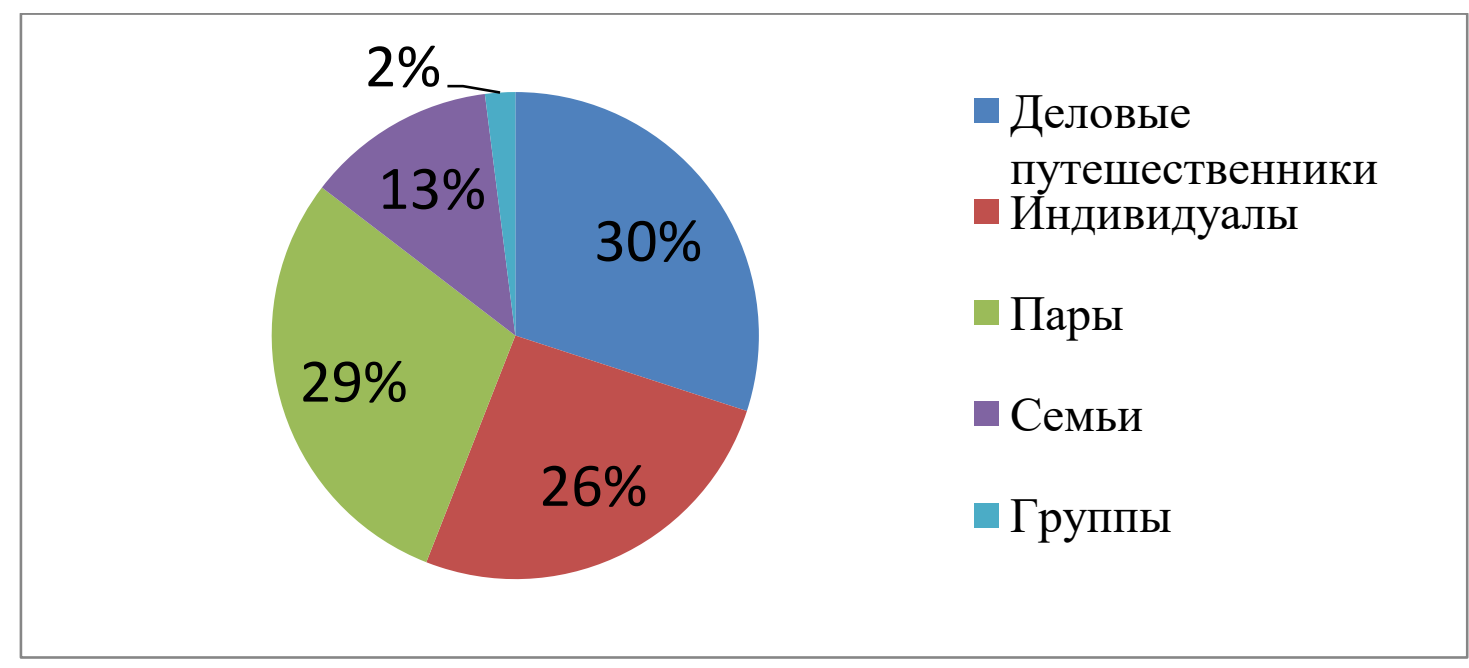

Рис. 1. Карта гостя по данным Booking.com

По данной таблице можно увидеть, что гостиницу «Courtyard by Marriott Paveletskaya» в основном посещают группы: «Деловые путешественники» (30\%); «Пары» (29\%) и «Индивидуалы» $(26 \%)$. Реже посещают «Семьи» $(13 \%)$ и «Группы» $(2 \%) .[6]$

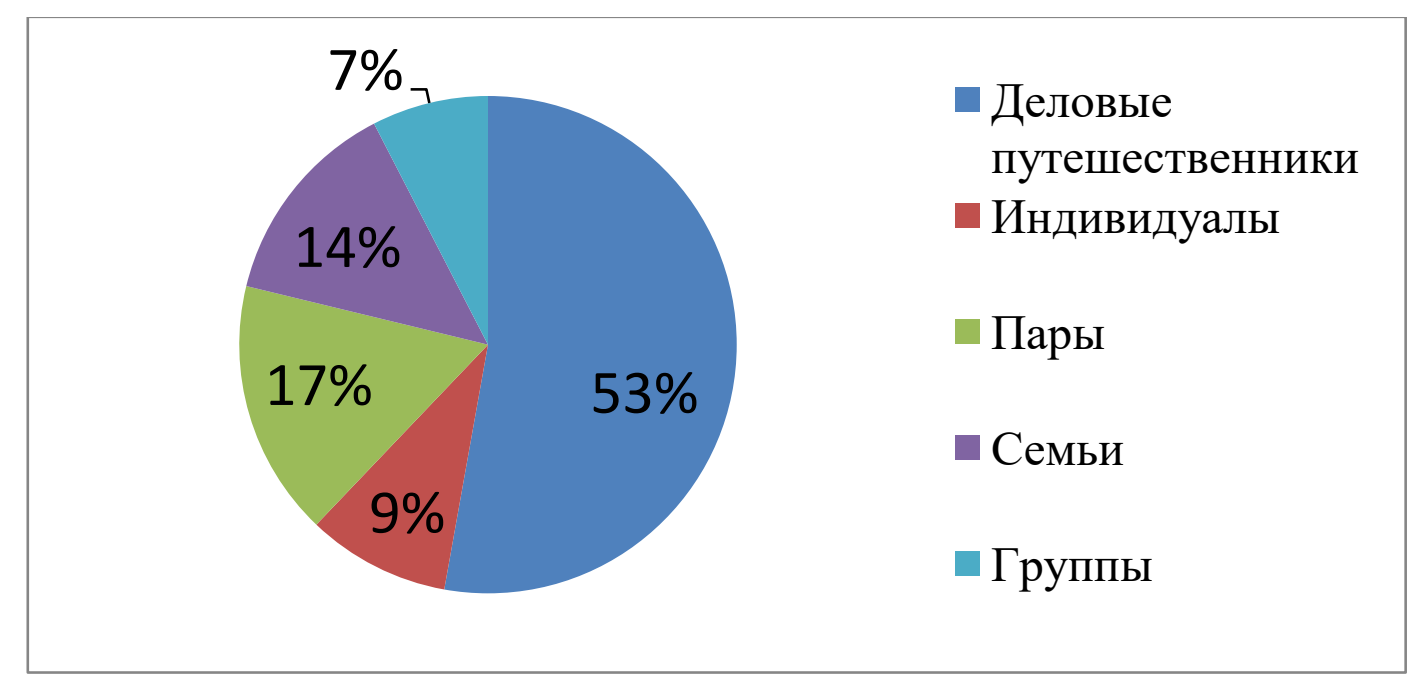

Рис. 2. Карта гостя по данным Tripadvistor.ru 
Проанализировав данные с Tripadvistor.ru, можно увидеть, что она сильно отличается от данных с Booking.com здесь показано, что большая часть гостей, заезжающих в гостиницу - это из группы «Деловые путешественники» составляет 53\%. Далее идут Пары (17\%); Семьи (14\%); «Индивидуалы» (9\%) и группы (7\%). [7]

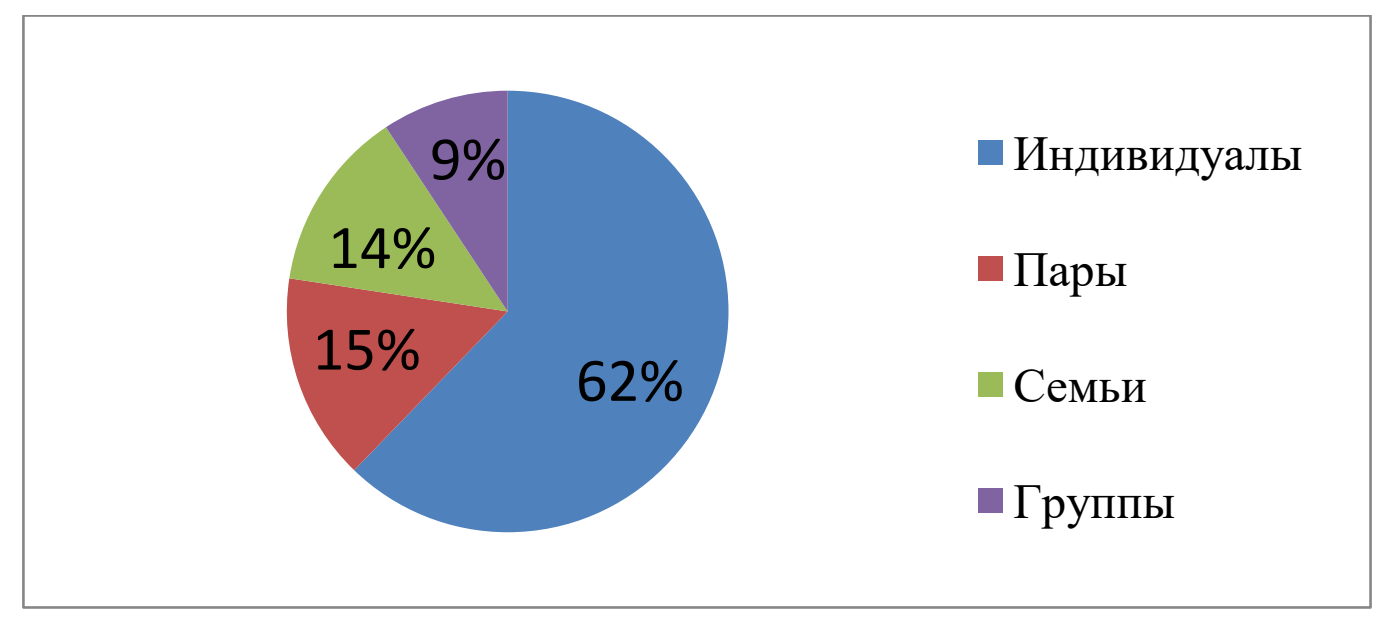

\section{Рис. 3. Карта гостя по данным marriott.com.ru}

Проанализировав данные с marriott.com.ru, можно сделать вывод, что она значительно отличается от предыдущих таблиц. Большая часть гостей, заезжающих в гостиницу - это группа «Индивидуалы» составляет 62\%. Далее идут Пары (15\%); Семьи (14\%) и группы (9\%). [8]

На основе проанализированных данных гостинице «Courtyard by Marriott Paveletskaya» следует обратить внимание на обслуживание гостей из категории «Деловые путешественники» и «Индивидуалы». Контроль качества для данных категорий не особо высок и в основном заключается в удобстве номера, наличие конференц-залов в организации деловых банкетов.

Проанализировав качество обслуживания гостей в гостинице «Courtyard by Marriott Paveletskaya» можно сделать вывод, что гостиница стоит устойчиво на рынке услуг и занимает высокие позиции и оценки своих гостей.

\section{Вывод.}

Анализ отзывов проводился с 3 сайтов: Booking.com, Tripadvistor.ru и marriott.com.ru. Данный анализ показывает, как менялся рейтинг гостиницы на данных сайтах.

Рейтинг гостиницы «Courtyard by Marriott Paveletskaya» довольно высок на каждом из выше данных сайтов, что характеризует ее как гостиницу с 
высоким качеством услуг и обслуживанием, с хорошо обставленными номерами и гибкой ценовой политиков.

\section{Список литературы}

1. Стандартизация и контроль качества гостиничных услуг: учебное пособие для бакалавров / Е.Ю. Никольская, Л.А. Попов, А.П. Ковальчук Москва: ФГБОУ ВО «РЭУ им. Плеханова», 2018. -172 с.

2. Никольская Е.Ю. Управление качеством гостиничных услуг // Никольская Е.Ю., Попов Л.А. - М.: Федеральное государственное бюджетное образовательное учреждение высшего образования «Российский экономический университет имени Г.В. Плеханова». 2019 - 200 с.

3. Герасимов, Б.Н. Управление качеством: Учебное пособие / Б.Н. Герасимов. - М.: Вузовский учебник, ИНФРА-М, 2015. - 304 с 